tion of the civil lunacy law has been done, it will at least constitute a convenient point of departure for the efforts of future law reformers, and it is now high time that the criminal lunacy law should be subjected to a similar process. A suitable opportunity for this salutary work being undertaken will occur when the reports of the Committees-which are investigating the rexed question of the criminal responsibility of the insane-are presented. We see no reason why the substantive and adjective laws of criminal lunacy should not be codified by the same Act.

\title{
The Death of Dr. D. Hack Tuke.
}

We feel that our readers would be disappointed if no notice, however short, were taken of the death of the chief editor of the Journal, so, though we purpose giving hereafter a full account of his life and work, we cannot allow the present number to go to press without expressing the great and irreparable loss which has been caused by the death of Dr. Tuke.

To our readers it is unnecessary to say more than that he was a prevading spirit of work, kindly feeling, and sympathy. He has been the chief editor of the Journal for nearly 18 years, and all contributors know his kindly consideration for them, while our readers know the value of the product.

He worked hard for his profession with no feeling of selfinterest, and if ever a man's good works follow him Dr. Tuke will have a rich harvest. We are tco near the loss to be able to estimate it yet, and we shall leave till a future number our true judgment of the man. We have lost a friend, and the profession has lost a painstaking, honest historian, who was ever helpful to those who were earnestly endearouring to follow truth.

He has been noticed to be failing for a year or more, and that his end was sudden was a blessing, we think, to him whose life had been spent in doing good honest work for humanity.

Many of his old friends stood by the grave-side at Saffron Walden to bid a long farewell to one who had ever borne the white flower of a blameless life. 